\title{
CONVENTIONAL AND ALTERNATIVE ANTIFUNGAL THERAPIES TO ORAL CANDIDIASIS
}

\section{Paula Cristina Anibal, Janaina de Cássia Orlandi Sardi, Iza Teixeira Alves Peixoto, Julianna Joanna de Carvalho Moraes, José Francisco Höfling*}

Departamento de Diagnóstico Oral, Faculdade de Odontologia de Piracicaba, Universidade Estadual de Campinas, Piracicaba, SP, Brasil.

Submitted: September 08, 2009; Approved: April 26, 2010.

\begin{abstract}
Candida-associated denture stomatitis is the most common form of oral candidal infection, with Candida albicans being the principal etiological agent. Candida adheres directly or via an intermediary layer of plaque-forming bacteria to denture acrylic. Despite antifungal therapy to treat denture stomatitis, infection is reestablished soon after the treatment ceases. In addition, many predisposing factors have been identified as important in the development of oral candidiasis, including malnourishment, common endocrine disorders, such as diabetis mellitus, antibacterial drug therapy, corticosteroids, radiotherapy and other immunocompromised conditions, such as acquired immunodeficiency syndrome (AIDS). These often results in increased tolerance to the most commonly used antifungals. So this review suggests new therapies to oral candidiasis.
\end{abstract}

Key words: Candida spp., antifungals, medicinal plants, extracts, essential oil.

\section{INTRODUCTION}

Candida species are commensal yeast in healthy humans and may cause systemic infections under immunocompromised situations due to its high adaptability to different host niches by the activation of appropriate sets of genes in response to complex environmental signals (1).

Denture stomatitis, also known as atrophic candidiasis, is the most common fungal infection in elder patients and in those who wear dentures. It is the result of a poor denture cleanliness, poor oral hygiene and wearing denture at night, which causes a decrease in the salivary flow below denture surface, thus facilitating the accumulation of characteristic biofilms (48).
Terai and Shimahara (51) have isolated species of Candida in the oral cavity and they found that the frequency does not necessarily imply disease in many healthy people without clinical manifestation, it just reflects that they may be carriers of Candida, with no infections.

Many predisposing factors have been identified as important in the development of oral candidiasis, including malnourishment, common endocrine disorders, such as diabetes mellitus, antibacterial drug therapy, corticosteroids, radiotherapy and other immunocompromised conditions, such as acquired immunodeficiency syndrome (AIDS) (49). Candida albicans is the most common species of yeasts isolated from patients with these predisposing factors (19) and non-albicans species have been isolated from the oral cavity of

*Corresponding Author. Mailing address: Faculdade de Odontologia de Piracicaba, Universidade Estadual de Campinas, Caixa Postal 52, CEP13414-903, Piracicaba, SP, Brazil.; Telefone: 5519 21065322.; E-mail: hofling@fop.unicamp.br 
immunocompromised patients, such as C. glabrata, C. krusei, C. parapsilosis, C. tropicalis, C. guilliermondii e $C$. dubliniensis (40).

Moreover, Candida may cause systemic infections associated with high mortality rates especially in immunocompromised patients that are particularly difficult to be cured of this kind of infection. This often happens because of the increased tolerance to the most commonly used azole antifungal drugs, including fluconazole and ketoconazole, generally observed in azole-resistant $C$. albicans infections (17, $47,58)$. So, several studies of new therapies with medicinal plants has been made to test the activity of their extracts, essential oils and active fractions against these microorganisms.

\section{Forms of Oral Candidiasis and Conventional Therapies}

Candida-associated denture stomatitis is the most common form of oral candidal infection (56), with Candida albicans being the main etiological agent (34). At least $65 \%$ of elderly denture-wearers carry Candida, and these yeasts have been isolated from $93 \%$ of patients with denture stomatitis. Candida adheres directly or via an intermediary layer of plaque-forming bacteria to denture acrylic (polymethylmethacrylate) (15). Despite antifungal therapy to treat denture stomatitis, infection is reestablished soon after the treatment ceases, suggesting that denture plaque may serve as a protected reservoir for $C$. albicans. Although multiple factors are likely to contribute to the development of denture stomatitis, it unequivocally involves denture plaque (12).

Since the 1980s, the imidazoles became increasingly more popular and seem to have replaced, to a large extent, the polyenes for the treatment of oral thrush. Miconazole and ketoconazole were found to be effective in in vitro denture liners, but they are more expensive and the toxicity of ketoconazole is a problem (44). Rapid relapse (7, 11), resistance and cross resistance between the azoles have also been reported, particularly in association with immunosuppressed individuals (16).

Reasons for the use of nystatin over other drugs in the treatment of fungal denture stomatitis still remain: Johnson et al. (23) in a clinical study showed nystatin (pastille) to be effective in reducing or eliminating the Candida organism associated with denture stomatitis; Truhlar et al. (53) showed that antifungal activity of nystatin in liners decreased with time, and that in vitro fungicidal activity was proportional to the concentration of nystatin administrated. The aim of antimycotic treatment is to reduce the acute candidal overgrowth to levels that can be controlled by the host's defences. Bergendal and Isacsson (6) reported that nystatin does not cure denture stomatitis and recolonization of the yeast occurs after cessation of drug therapy.

Braga et al. (10) found that fluconazole in subinhibitory concentration was inactive to interfere in the adhesion ability of C. glabrata, and in studies of Lyon and Resende (27) a reduction in the adherence ability of C. glabrata, $C$. tropicalis and $C$. parapsilosis to buccal epithelial cells after exposure to fluconazole occurred, both among the isolates obtained from the denture-wearers with signs of oral candidiasis and normal palatal mucosa, considering that $C$. glabrata frequently shows high minimum inhibitory concentrations (MIC) to fluconazole, demonstrating the impact of this drug in the adherence ability of Candida yeast.

Antimicrobial resistance is a common phenomenon in cells recovered from biofilms (43). Chandra et al. (12) demonstrated increased resistance of $C$. albicans biofilms grown on denture acrylic to fluconazole, amphotericin B, nystatin and chlorhexidine. Furthermore, C. albicans cells resuspended from a biofilm typically maintain some degree of resistance to antimicrobials compared to planktonic cells (5). Candida albicans cells resuspended from a mature biofilm maintained fluconazole resistance even after the biofilm had been disrupted (45). Treatment methods directed towards reducing initial fungal attachment and subsequent biofilm development on denture acrylic would be beneficial in reducing the incidence and severity of this condition (43).

Exposure of Candida to chlorhexidine results in loss of structural integrity, less ability to adhere, and fragmentation of the cell wall (28). A notable feature of chlorhexidine is that it 
adheres to salivary glycoproteins in plaque and is slowly released over time. Following a $1 \mathrm{~min}$ rinse with chlorhexidine, $30 \%$ was retained in the oral cavity for $24 \mathrm{~h}$ (8). This pharmacologic feature of chlorhexidine permits extended activity following exposure in the oral environment and allows a wide spacing of doses (43).

\section{Resistance in Immunocompromised Patients}

Powderly et al. (42) observed that Candida isolated from AIDS patients showed higher MIC values compared to those obtained from other patients, including the occurrence of isolates resistant to amphotericin B. Macura (29) observed resistance to nystatin in $2 \%$ of Candida spp. isolates from hospitalized patients. Costa et al. (13) evaluated the antifungal susceptibility profile of oral isolates obtained from HIV patients in a Brazilian hospital and found $8.1 \%$ of resistance to fluconazole and itraconazole and all isolates are susceptible to amphotericin B.

According to Alves et al. (3), the presence of yeast resistant to polyenes is frequent in neutropenic patients, especially $C$. tropicalis and $C$. lusitaniae. The resistance of $C$. tropicalis to polyenes was also reported by Resende and Resende (46), considering samples obtained from hospitalized patients. In studies of Pinto et al. (41), C. albicans resistant to amphotericin B was isolated from HIV patients, urine samples and from a diabetes mellitus patient. A significant number (30\%) of resistant C. parapsilosis isolated from HIV patients, newborns, and from nail was observed.

For Nakamura and Takahashi (32), C. parapsilosis was the major fungi isolated from hospitalized patients in Japan, followed by $C$. albicans and all of those isolates were susceptible to fluconazole. Fluconazole has been frequently used due to its lower toxicity compared to amphotericin B. Viscoli (54) stated that fluconazole is effective and less toxic than amphotericin B. According to these authors, resistance to fluconazole is not very common in short treatments, however in immunocompromised patients under long-term therapy, the substitution of susceptible species by naturally resistant ones is observed. The increasing incidence of fungal infections and widespread use of the newer oral triazoles have led to a resurgence of interest in antifungal resistance for these agents.

\section{Mechanism of Action of the Antifungal Drugs}

Polyenes, ergosterol biosynthesis inhibitors and 5flucytosin (5-FC) are three common classes of antifungal agent. The first two classes of drug act against ergosterol directly in some way. Ergosterol is the major sterol of the fungal plasma membrane that regulates the fluidity and asymmetry of the membrane, and it is important for the proper functioning of many membrane-bound enzymes (24). Polyenes, including amphotericin B and nystatin, target membranes which contain ergosterol. From the 1950s, amphotericin B has been the "best drug" used in therapy for severe systemic mycoses.

Ergosterol biosynthesis inhibitors include three groups of antifungal agent: allylamines, such as naftifine and terbinafine; thiocarbamates, such as tolnaftate and tolciclate; and azolebased, such as imidazoles (including ketoconazole and miconazole) and triazole (including fluconazole, itraconazole, and voriconazole). These drugs interact with enzymes involved in the synthesis of ergosterol from squalene. Both allylamines and thiocarbamates inhibit early steps of ergosterol byosinthesis. The major target of azole-based drugs is cytochrome P-450 enzyme (lanosterol 14- $\alpha$ - demethylase) (24), encoded by the ERG11 gene (25).

Flucytosine (5-fluorocytosine) works as an antifungal agent through conversion to 5-fluorouracil within target cells. Fluorouracil becomes incorporated into RNA, causing premature chain termination, and inhibits DNA synthesis through effects on thymidylate synthase. The useful spectrum of flucytosine is restricted to pathogenic yeasts (Candida species and Cryptococcus neoformans) and is used as adjunctive, rather than as primary therapy in the clinic because of primary and secondary resistance (36).

There are six new antifungal agents that are currently generating excitement as they pass through the final developmental stages of clinical trials. Three of them (posaconazole, ravuconazole and voriconazole) are triazole 
compounds, a subset of the azoles, which are the most successful antifungal class in the clinic since the late 1960s. The other three (anidulafungin, caspofungin and micafungin) are echinocandins and are successors to cilofungin, which was abandoned in the 1980s. The echinocandins inhibit synthesis of fungal $\beta-1,3$ glucan, and this represents the first novel target in 20 years of antifungal drug discovery in terms of clinically useful drugs (36).

Any novel antifungal agent needs to have as broad a spectrum of susceptible fungal species as possible, whatever its mechanism of action. Genomics-based target searches must therefore emphasize genes that are widely represented in the fungal kingdom, but are absent or of a demonstrably different structure in mammalian cells. If a target is shared between host and pathogen, additional constraints are placed on the selectivity and toxicity of potential antifungal agents. This reduces the apparently large number of potentially useful targets that is found from genomics searches based only on $C$. albicans and S. cerevisiae (36).

\section{Development of Resistance}

The chronic use of azole compounds in the prevention of systemic mycosis, especially in patients with HIV infection, allows the selection of resistant isolated to this therapy (35). The widespread use of antibiotics is attributed to promote the superinfection of the yeasts from periodontal pockets as a result of the disturb caused in commensal microflora homeostase (20) and many currently available antifungal drugs have several problems including side effects, being ineffective against some fungi. An increase number of reports of clinical resistance to antifungal agents highlight the need for understanding the molecular mechanisms responsible for the development of drug resistance (62).

The molecular mechanisms that result in azole resistance include overexpression of (i) the major facilitator efflux pump gene MDR1, (ii) the ABC transporter efflux pump CDR gene family, and (iii) the azole target enzyme gene ERG11. Point mutations in ERG11 are also important for resistance. This molecular mechanism of resistance may occur simultaneously or independently of each other and exists in different combinations (60). In clinical isolates from HIV-positive patients, there is a correlation between azole drug resistance and overexpression of the MDR1 gene (59).

Orozco et al (37) determined the mechanism for the primary resistance of $C$. krusei to fluconazole: $C$. krusei has the capacity to efflux fluconazole out of cells better than $C$. albicans. A higher concentration of fluconazole is needed to inhibit the synthesis of ergosterol to the same extent in cell extracts from $C$. krusei than in those from $C$. albicans. This result suggested that in addition to efflux, the affinity of fluconazole to the target enzymes of these two species is also different.

\section{New Antimicrobial Therapies}

Due to the increasing resistance of microorganisms to antibiotics administrated, which no longer fully meet the medical necessity with respect to spectrum, potency, safety and pharmacokinetic properties, increasing the incidence of systemic fungal infections, with consequent increase in mortality, it is necessary to search for new compounds to act against these microorganisms, but in a selective and low toxicity way. Thus, several studies of medicinal plants have been made to test the activity of their extracts, essential oils and fractions act against these microorganisms.

The problem of the microbial resistance is increasing and the future perspective of production and use of antimicrobial drugs continue uncertain. Thus, the use of products from vegetal origin with potential antimicrobial activity can acquire meaning in therapeutical treatments $(26,39)$. The medicinal plants are frequently used in the treatment of some illnesses and, recently, have been intensely studied as alternative agents for the prevention of diseases, as oral diseases (38). Natural products fields produced, approximately, 50\% new chemical molecules in the years of 2000 - 2006, as well as have demonstrated its importance in the development of drugs for the treatment of diseases (33).

Medicinal plants are, however, a rich source of novel, complex, and diverse chemical structures, which warrants their 
more thorough investigation as a potential source of novel antifungal agents. The identification of the medicinal plant extracts active against Candida isolates of reduced azole susceptibility and showing pathogen selectivity is important from a practical point of view (50).

The antifungal compounds of plants are not well known; however, the presence of flavonoids and terpenes and a certain degree of lipophilicity might determine toxicity by the interactions with the membrane constituents and their arrangement (52).

Many extracts of plants and isolated essential oils have demonstrated to exert biological activity in vivo and in vitro (31). Natural products have been recently investigated more thoroughly as promising agents for the prevention of oral diseases, especially plaque-related diseases such as dental caries $(18,38)$.

Here, we demonstrated some studies in which vegetable extracts presented activity. Mardegan (30) analyzed the antifungal activity of some vegetable extracts against strains of Candida albicans isolated from healthy children and adults with periodontal disease, and observed inhibition of these clinical samples and on their proteolitic enzymes through extracts of Mentha piperita, Tabebuia avellanedae, Casearia sylvestris, Arctium lappa, Arrabidae chica e Rosmarinus officinalis.

Anibal (4) observed activity against strains of $C$. albicans CBS-562, C. dubliniensis CBS-7987, C. parapsilosis CBS-604, C. tropicalis CBS-94, C. guilliermondii CBS-566, C. utilis CBS-5609, C. krusei CBS-573, C. lusitaniae B-06, C. glabrata B-07 and C. rugosa B-12 with the extracts of Mentha piperita, Arrabidaea chica, Rosmarinus officinalis, Tabebuia avellanedae, Syzygium cumini and Punica granatum. Some of these plants, such as A. chica, R. officinalis, S. cumini, and $P$. granatum, present among several other compouds, tannins that have remarkable antimicrobial activity (22)

The yeast $C$. albicans, frequently associated with infections in HIV (+) patients, was the most sensitive among all tested microorganisms. Lippia sidoides essential oil showed an appreciable amount of monoterpenes, a therapeutical potential that should not be ignored, and its phenolic compounds (thymol and carvacrol) showed activity against oral pathogens (9).

Duarte et al. (13) observed that the oil of Achillea millefolium, Mikania glomerata and Stachys byzantina have a strong activity against $C$. albicans, while Aloysia triphylla, Anthemis nobilis, Cymbopogon martini, Cyperus articulates, Cyperus rotundus, Lippia alba, Mentha arvensis and Mentha piperita showed moderate activity.

In a work of Hirasawa and Takada (21), using a catechin ()-epigallocatechin gallate combined with amphotericin B, it was observed the inhibited growth of $C$. albicans, and that the action was fungicidal. Amphotericin B below the Minimal Fungicidal Concentration also stimulates fungal membrane permeability. The combined use of amphotericin B and catechin may stimulate catechin uptake into the cell by the action of amphotericin B, and intracellular catechin may act as a fungicidal agent.

Zhang et al. (63) observed that the fractions TTS-12 and TTS-15 of Tribulus terrestris L. had significant antifungal activities against the five yeasts tested: $C$. albicans, $C$. glabrata, C. parapsilosis, C. tropicalis, Cryptococcus neoformans. The experiment showed that TTS-12 and TTS-15 had potent anti-Candida albicans activity, where MIC80 was 1.0 and $2.3 \mu \mathrm{g} / \mathrm{mL}$, respectively. The steroidal glycosides tested in the experiment are from the same chemical class, but only TTS-12 and TTS-15 exhibited significant antifungal activity against that cited yeasts. These results indicate that there are critical structural features that are responsible for the antifungal activity.

As plants produce many compounds with antimicrobial properties, it is expected that some programs of valuation to antifungal activity may indicate these compounds to the development of these new antimicrobial drugs (2). A successful therapy can be defined as "a suitable agent prescribed to treat the right organism at appropriate dosage". Epidemiological studies by surveillance to determine the true frequency of antifungal resistance may be the first step to control the emergence of antifungal resistance. Rapid 
identification of fungal pathogens and the measurement of the MIC of clinical isolates in vitro may be helpful. Knowledge gained from studying the mechanisms of antifungal resistance may provide ideas on how to limit the emergence of resistance to those marketed antifungal agents and to develop safer and better compounds for the next generation of antifungal agents (62). New treatment strategies, especially those active against azole-resistant isolates, are urgently needed.

\section{CONCLUSION}

We presented in this review the necessity to develop new therapy agents against opportunistic fungi of the Candida genera which, as other microorganisms, have the ability to acquire resistance to antimicrobians during prolonged treatment, especially in immunocompromised patients. One of the most promissory sources to the research of new agents is found in plants, which have compounds with antimicrobians properties that is being studied by diverse researchers, but many of these compounds are not known yet. The investigation of these active principles, once they have different targets that were found in the antifungal in use, is a potential area that must be studied.

\section{REFERENCES}

1. Abad, M.J.; Anseategui, M.; Bermejo, P. (2007). Active antifungal substance from natural sources. Arkivoc. 7, 116-145.

2. Ahmad, I.; Beg, A.Z. (2001). Antimicrobial and phytochemical studies on 45 Indian medicinal plants against multi-drug resistant human pathogens. J. Ethnopharmacol. 74, 113-123.

3. Alves, S.H.; Lopes, J.O.; Cury, A.E. (1997). Teste de Susceptibilidade aos Antifúngicos: Por que, quando e como realizar. News Laboratory. 6, 140-148.

4. Anibal, P.C. (2007). Potencial de ação antimicrobiana in vitro de extratos brutos de plantas na inibição de Candida spp, Streptococcus mutans e Staphylococcus aureus. Piracicaba, Brasil, 76p. (M.Sc. Dissertation. Faculdade de Odontologia de Piracicaba. UNICAMP).

5. Baillie, G.S.; Douglas, L.J. (1998). Effect of growth rate on resistance of Candida albicans biofilms to antifungal agents. Antimicrob. Agents Chemother. 42, 1900-1905.

6. Bergendal, T.; Isacsson, G. (1980). Effect of nystatin in the treatment of denture stomatitis. Scand. J. Dent. Res. 88, 446-454.
7. Bissell, V.; Felix, D.H.; Wray, D. (1993). Comparative trial of fluconazole and amphotericin in the treatment of denture stomatitis. Oral Surg. Oral Med. Oral Pathol. 76, 35-39.

8. Bonesvoll, P.; Lokken, P.; Rolla, G.; Paus, P.N. (1974). Retention of chlorhexidine in the human oral cavity after mouth rinses. Arch. Oral Biol. 19, 209-212.

9. Botelho, M.A.; Nogueira, N.A.P.; Bastos, G.M.; Fonseca, S.G.C.; Lemos, T.L.G.; Matos, F.J.A.; Montenegro, D.; Heukelbach, J.; Rao, V.S.; Brito, G.A.C. (2007). Antimicrobial activity of the essential oil from Lippia sidoides, carvacrol and thymol against oral pathogens. Braz. J. Med. Biol. Res. 40, 349-356.

10. Braga, P.C.; Maci, S.; Dal Sasso, M.; Bohn, M. (1996). Experimental evidences for a role of subinhibitory concentrations of rilopirox, nystatin and fluconazole on adherence of Candida spp. to vaginal epithelial cells. Chemotherapy. 4, 259-265.

11. Budtz-Jorgensen, E.; Holmstrup, P.; Krogh, P. (1988). Fluconazole in the treatment of Candida-associated denture stomatitis. Antimicrob. Agents Chemother. 32, 1859-1863.

12. Chandra, J.; Mukherjee, P.K.; Leidich, S.D.; Faddoul, F.F.; Hoyer, L.L.; Douglas, L.J.; Ghannoum, M.A. (2001). Antifungal resistance of candidal biofilms formed on denture acrylic in vitro. J. Dent. Res. 80, 903-908.

13. Costa, C.R.; de Lemos, J.A.; Passos, X.S.; de Araujo, C.R.; Cohen, A.J.; Souza, L.K.; Silva M.R. (2006). Species distribution and antifungal susceptibility profile of oral Candida isolates from HIV-infected patients in the antiretroviral therapy era. Mycopathologia. 162, 45-50.

14. Duarte, M.C.T.; Figueira, G.M.; Sartoratto, A.; Rehder, V.L.G.; Delarmelina, C. (2005). Anti-Candida activity of Brazilian medicinal plants. J. Ethnopharmacol. 97, 305-311.

15. Edgerton, M.; Scannapieco, F.A.; Levine, M.J. (1993). Human submandibular-sublingual saliva promotes adhesion of Candida albicans to polymethylmethacrylate. Infect. Immun. 61, 2644-2652.

16. Ellepola, A,N.; Samaranayake, L.P. (2000). Antimycotic agents in oral candidosis: an overview: 1. Clinical variants. Dent. Update. 27, 111-112, 114-116.

17. Ellis, D. (2002). Amphotericin B: spectrum and resistance. J. Antimicrob. Chemother. 20, 7-10.

18. Fernandes-Filho, E.S.; Morais, S.M.; Fonseca, S.G.; Mota, O.M. (1998). Preparação e avaliação clínica do óleo essencial da planta medicinal Lippia sidoides Cham (Alecrim-pimenta). Rev. Ass. Bras. Odonto. 6, 323-325.

19. Fidel, P.L. Jr. (2006). Candida host interactions in HIV disease: relationships in oropharyngeal candidiasis. Adv. Dent. Res. 19, 80-84.

20. Helouvo, H.; Hakkarainen, K.; Paunio, K. (1993). Changes in the prevalence of subgingival enterics rods, staphylococci and yeasts after treatment with penicillin and erythromycin. Oral Microbiol. Immunol. 8, 75-79.

21. Hirasawa, M.; Takada, K. (2004). Multiple effects of green tea catechin on the antifungal activity of antimycotics against Candida albicans. J. 
Antimicrob. Chemother. 53, 225-229.

22. Hussein, S.A.M.; Barakat, H.H.; Merfort, I.; Nawwar, M.A.M. (1997). Tannins from the leaves of Punica granatum. Phytochemistry. 45, 819823.

23. Johnson, G.H.; Taylor, T.D.; Heid, D.W. (1989) Clinical evaluation of a nystatin pastille for treatment of denture-related oral candidiasis. $J$. Prosthet. Dent. 61, 699-703.

24. Joseph-Horne, T.; Hollomon, D.W. (1997). Molecular mechanisms of azole resistance in fungi. FEMS Microbiol. Lett. 149, 141-149.

25. Lai, M.H.; Kirsch, D.R. (1989). Nucleotide sequence of cytochrome P450 L1A1 (lanosterol 14 alpha-demethylase) fromCandida albicans. Nucleic. Acids Res. 17, 804.

26. Loguercio, A.P.; Battistin, A.; Vargas, A.C.; Henzel, A.; Witt, N.M. (2005). Atividade antibacteriana de extrato hidro-alcoólico de folhas de jambolão (Syzygium cumini L. Skells). Ciência Rural. 35 (2), 371-376.

27. Lyon, J.P.; Resende, M.A. (2007). Evaluation of adhesion to buccal epithelial cells in Candida species obtained from denture wearers after exposure to fluconazole. Mycoses. 50 (1), 21-24.

28. MacNeill, S.; Rindler, E.; Walker, A.; Brown, A.R.; Cobb, C.M. (1997) Effects of tetracycline hydrochloride and chlorhexidine gluconate on Candida albicans: an in vitro study. J. Clin. Periodontol. 24, 753-760.

29. Macura, A.B. (1991). Fungal resistance to antimycotic drug: a growing problem. Int. J. Dermatol. 30, 181-183.

30. Mardegan, R.C. (2007). Atividade inibitória de extratos vegetais sobre Candida spp e sobre proteinases sintetizados por Candida albicans. Piracicaba, Brasil, 93p. (D.Sc. Thesis. Faculdade de Odontologia de Piracicaba. UNICAMP).

31. Martinez, M.J.; Betamcourt, J.; Alonso-González, N.; Jauregui, A (1996). Screening of some Cuban medicinal plants for antimicrobia activity. J. Ethnopharmacol. 52, 171-174.

32. Nakamura, T.; Takahashi, H.; (2006). Epidemiological study of Candida infections in blood: susceptibilities of Candida spp. to antifungal agents, and clinical features associated with the candidemia. J. Infect. Chemother. 12, 132-138.

33. Newman, D.J.; Cragg, G.M. (2007). Natural products as source of new drugs over the last 25 years. J. Nat. Prod. 70, 461-477.

34. Nikawa, H.; Hamada, T.; Yamamoto, T. (1998). Denture plaque-past and recent concerns. J. Dent. 26, 299-304.

35. Odds, F.C. (1993). Resistance of yeasts to azole-derivative antifungal. $J$. Antimicrob. Chemother. 31(4):463-71.

36. Odds, F.C.; Brown, A.J.P.; Gow, N.A.R. (2003). Antifungal agents: mechanisms of action. TRENDS in Microbiology. 11 (6), 272-279.

37. Orozco, A.S.; Higginbotham, L.M.; Hitchcock, C.A.; Parkinson, T.; Falconer, D.; Ibrahim, A.S.; Ghannoum, M.A.; Filler, S.G. (1998). Mechanism of fluconazole resistance in Candida krusei. Antimicrob. Agents Chemother. 42, 2645-2649.

38. Pai, M.R.; Acharya, L.D.; Udupa, N. (2004). Evaluation of antiplaque activity of Azadirachta indica leaf extract gel - a 6-week clinical study. J. Ethnopharmacol. 90, 99-103.
39. Patel, M.; Shacleton, J.T.; Coogan, M.M. (2006). Effect of antifungal treatment on the prevalence of yeasts in HIV-infected subjects. J. Med. Microbiol. 55, 1279-1284.

40. Pfaller, M.A.; Jones, R.N.; Doern, G.V.; Sader, A.S.; Messer, SA.; Houston, A.; Coffman, S.; Hollis R.J. (2000). Bloodstream infections due to Candida species: SENTRY antimicrobial surveillance program in North America and Latin America, 1997-1998. Antimicrob. Agents Chemother. 44, 747-751.

41. Pinto, P.M.; Weikert-Oliveira, R.C.B.; Lyon, J.P.; Cury, V.F.; Arantes, R.R.; Koga-Ito, C.Y.; Resende, M.A. (2008). In vitro antifungal susceptibility of clinical isolates of Candida spp. obtained from patients with different predisposing factors to candidosis. Microbiol. Res. 163 (5), 579-585.

42. Powderly, W.G.; Kobayashi, G.S.; Herzig, G.P.; (1988). Amphotericin B-resistant yeasts infection in severely immunocompromised patients. Am. J. Med. 84, 826-832.

43. Pusateri, C.R.; Monaco, E.A.; Edgerton, M. (2009). Sensitivity of Candida albicans biofilm cells grown on denture acrylic to antifungal proteins and chlorhexidine. Arch. Oral Biol. 54 (6), 588-594.

44. Quinn, D.M. (1985). The effectiveness, in vitro, of miconazole and ketoconazole combined with tissue conditioners in inhibiting the growth of Candida albicans. J. Oral Rehabil. 12, 177-182.

45. Ramage, G.; Bachmann, S.; Patterson, T.F.; Wickes, B,L.; Lopez-Ribot, J.L. (2002). Investigation of multidrug efflux pumps in relation to fluconazole resistance in Candida albicans biofilms. J. Antimicrob. Chemother. 49, 973-980.

46. Resende, J.C.P.; Resende, M.A. (1999). In vitro antifungal susceptibility of clinical isolates of Candida spp. from hospitalized patients. Mycoses. 42, 641-644.

47. Ruhnke, M. (2006). Epidemiology of Candida albicans infections and role of non-Candida-albicans yeasts. Curr. Drug Targets. 7, 495-504.

48. Samaranayake, L.P.; Nair, R.G. (1995). Oral candida infection - A Review. Indian J. Dent. Rest. 6, 69-82.

49. Samaranayake, L.P.; Cheung, L.K.; Samaranayake, Y.H. (2002). Candidiasis and other fungal disease of the mouth. Dermatol. Ther. 15, 251-269.

50. Spelman, K.; Duke, J.A.; Bogenschutz-Godwin, M.J. (2008). The synergy principle at work with plants, pathogens, insects, herbivores and humans. In: Cseke, L.J., Kirakosyan, A., Kaufman, P.B. (eds). Natiral Products from Plants. CRC Press, India, p. 475-495.

51. Terai, H.; Shimahara, M. (2009). Usefulness of culture test and direct examination for the diagnosis of oral atrophic candidiasis. Int. J. Dermatol. 48, 371-373.

52. Tomas-Barberan, F.; Iniesta-Sanmartin, E.; Tomas-Lorente, F.; Rumbero, A. (1990). Antimicrobial phenolic compounds from three Spanish Helichrysum species. Phytochemistry. 29, 1093-1095.

53. Truhlar, M.R.; Shay, K.; Sohnle, P. (1994). Use of a new assay technique for quantification of antifungal activity of nystatin incorporated in denture liners. J. Prosthet. Dent. 71, 517-524. 
54. Viscoli, C. (1996). Fluconazole versus amphotericina B as empirical antifungal therapy of unexplained fever in granulocytopenic cancer patients: a progmatic, multicentre, prospective and randomized clinical trial. Eur. J. Cancer. 3, 814-820.

55. Warnock, D.W. (1992). Azole drug resistance in Candida species. J. Med. Microbiol. 37, 225-226.

56. Webb, B.C.; Thomas, C.J.; Harty, D.W.; Willcox, M.D. (1998). Effectiveness of two methods of denture sterilization. J. Oral Rehabil. 25, 416-423.

57. Webb, B.C.; Thomas, C.J.; Willcox, M.D.; Harty, D.W.; Knox, K.W. (1998). Candida-associated denture stomatitis. Aetiology and management: a review. Part 2. Oral diseases caused by Candida species. Aust. Dent. J. 43, 160-166.

58. Wenzel, R.P. (1995). Nosocomial candidemia: risk factors and attributable mortality. Clin. Infect. Dis. 20, 1531-1534.
59. White, T.C.; Holleman, S.; Dy, F.; Mirels, L.F.; Stevens, D.A. (2002). Resistance mechanisms in clinical isolates of Candida albicans. Antimicob. Agents Chemother. 46, 1704-1713.

60. White, T.C.; Marr, K.A.; Bowden, R.A. (1998). Clinical, cellular, and molecular factors that contribute to antifungal drug resistance. Clin. Microbiol. Rev. 11, 382-402.

61. Xu, T.; Levitz, S.M.; Diamond, R.D.; Oppnheim, F.G. (1991). Anticandidal activity of major human salivary histatins. Infect. Immun. 59, 2549-2554.

62. Yang, Y.L.; Lo, H.J. (2001). Mechanisms of antifungal agents resistance. J. Microbiol. Immunol. Infect. 34, 79-86.

63. Zhang, J.D.; Xu, Z.; Cao, Y.B.; Chen, H.S.; Yan, L.; An, M.M.; Gao, P.H.; Wang, Y.; Jia, X.M.; Jiang, Y.Y. (2006). Antifungal activities and action mechanisms of compounds from Tribulus terrestris L. J. Ethnopharmacol. 103 (1), 76-84. 